\title{
Performance of a new flexible 19 G EUS needle in pancreatic solid lesions located in the head and uncinate process: A prospective multicenter study
}

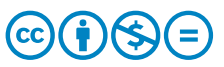

\section{Authors}

Angels Ginès 1,2,3, Pietro Fusaroli ${ }^{4}$, Oriol Sendino ${ }^{1,2,3}$, Andrada Seicean ${ }^{5}$, Antonio Z. Gimeno-Garcia ${ }^{6}$, Jordi GratacósGinès ${ }^{1}$, Isis K. Araujo ${ }^{1,3}$, Leonardo Rodríguez-Carunchio ${ }^{7}$, Silvia Alós ${ }^{7}$, Andrea Lisotti ${ }^{4}$, Anna Cominardi ${ }^{4}$, Andrea Montenegro', Glòria Fernández-Esparrach1,2,3

Institutions

1 Hospital Clinic de Barcelona - Endoscopy Unit, Barcelona. University of Barcelona, Spain

2 CIBEREHD Barcelona, Spain

3 IDIBAPS - Medicina, Barcelona, Spain

4 Hospital of Imola - GI Unit, University of Bologna, Imola, Italy

5 University of Medicine and Pharmacy - Regional Institute of Gastroenterology and Hepatology, ClujNapoca, Romania

6 Hospital Universitario de de Sta Cruz de Tenerife Service of Gastroenterology, Tenerife, Spain

7 Hospital Clinic de Barcelona - Pathology Department, University of Vic - Central University of Catalonia (UVicUCC), Barcelona, Spain

submitted 23.1.2021

accepted after revision 22.3.2021

Bibliography

Endosc Int Open 2021; 09: E1269-E1275

DOI 10.1055/a-1480-0428

ISSN 2364-3722

(c) 2021. The Author(s).

This is an open access article published by Thieme under the terms of the Creative Commons Attribution-NonDerivative-NonCommercial License, permitting copying and reproduction so long as the original work is given appropriate credit. Contents may not be used for commercial purposes, or adapted, remixed, transformed or built upon. (https://creativecommons.org/licenses/by-nc-nd/4.0/)

Georg Thieme Verlag KG, Rüdigerstraße 14,

70469 Stuttgart, Germany

Corresponding autor

Dr. Angels Gines, Hospital Clinic, Villarroel 170, 08036

Barcelona, Spain

Fax: +0034932279850

MAGINES@clinic.cat

\section{ABSTRACT}

Background and study aims The poor flexibility of largebore EUS needles often leads to technical failure when sampling from the duodenum. The aim of this study was to evaluate the technical and diagnostic performances of a new Menghini tip 19G nitinol EUS needle for sampling pancreatic solid lesions in the head and uncinate process.

Patients and methods This was a European prospective multicenter single-arm study. A maximum of four passes were allowed. In case of failure, different needles were permitted.

Results We included 75 patients ( $51 \%$ males) with lesions in the head $(n=68 ; 91 \%)$ and uncinate process $(n=7 ; 9 \%)$ (mean size: $33 \pm 12 \mathrm{~mm}$; number of passes: $1.8 \pm 0.9$ ). Technical success was seen in 71 of 75 (94.7\%). Diagnostic rates were $89.3 \%(67 / 75)$ and $94.4 \%(67 / 71)$ in the intention-totreat (ITT) and per-protocol (PP) analysis, respectively. In the eight cases with failure, diagnosis was obtained with another needle $(n=4)$, from another lesion $(n=3)$ or with follow-up $(n=1)$. A histological sample was obtained in 64 patients (ITT $85.3 \%$ and PP $90 \%$ ) and immunohistochemistry was successfully performed in 13 of 15 lesions in which it was required. No differences between rapid on-site evaluation (ROSE) and non-ROSE groups were observed regarding diagnostic success ( $87.5 \%$ vs $91 \%, P=0.582$ ) and diagnosis at the first pass ( $70 \%$ vs $81 \%, P=0.289)$. Number of passes was lower in the ROSE group $(1.4+0.9$ vs $2.2+0.7, P<$ $0.001)$. One adverse event was recorded (1.3\%) consisting in a duodenal perforation after a single session EUS-ERCP. Conclusions The new nitinol Menghini tip 19G EUS needle showed high technical diagnostic success in safely sampling solid lesions in the head and uncinate process of the pancreas. 


\section{Introduction}

Endoscopic ultrasound (EUS)-guided tissue acquisition is useful and safe for assessing cytological or histological diagnosis of pancreatic solid tumors [1-5]. However, despite the availability of different needles, it remains technically challenging to sample tumors in the head/uncinate process of the pancreas using large bore EUS fine-needle biopsy (FNB) needles from the duodenum [6]. The need for large-bore needles depends on pathologist preference, unavailability of rapid on-site evaluation (ROSE), and/or when the preservation of tissue architecture and morphology is necessary for the diagnosis [7, 8]. Moreover, a good tissue core provides enough tissue for ancillary techniques such as immunohistochemistry [9].

Although the impact of ROSE in the accuracy of EUS fineneedle aspiration (EUS-FNA) is controversial [10-13], many centers, as suggested by guidelines, successfully use ROSE to improve diagnostic adequacy of EUS-FNA and reduce the number of needle passes [14-15]. The potential of ROSE to reduce the number of needle passes was also shown in two randomized studies $[12,13]$. In this context, using EUS-FNB needles could overcome the problem by providing a core biopsy for analysis [16].

The technical difficulty of using $19 \mathrm{G}$ needles with the torqued position of the echoendoscope when sampling the head or uncinated process of the pancreas from the duodenum is well known. In one randomized clinical trial (RCT) comparing $19 \mathrm{G}$ and $22 \mathrm{G}$ needles, the former provided better diagnostic accuracy but also a significantly higher technical failure rate in case of pancreatic head tumors [17]. In the same way, in a recent study of 548 patients who underwent EUS-FNA, the $25 \mathrm{G}$ needle had superior technical performance over the $19 \mathrm{G}$ and $22 \mathrm{G}$ needles for sampling from the duodenum [10].

New nitinol-based needles have been developed with enhanced flexibility to improve the technical success of transduodenal sampling [18-20]. Nevertheless, a recent RCT comparing a flexible 19 G vs. a standard 22 G needle in pancreatic head lesions failed to show any advantage of using the larger needle at intention-to-treat analysis (diagnostic accuracy for malignancy $69.5 \%$ vs $87.3 \%$, respectively; $P=0.02$ ). Considering only the cases of technical success with the $19 \mathrm{G}$ needle, the accuracy was noninferior to the $22 \mathrm{G}(80.4 \%$ vs $87.3 \%$; $P=n s)$ [21].

The objective of this study was to assess the technical performance and diagnostic accuracy of a new nitinol $19 \mathrm{G}$ needle (EZShot 3 Plus, Olympus, Tokyo, Japan) for sampling lesions in the pancreatic head and uncinate process. The new needle has a multilayer coil sheath and a tip with a Menghini design. Theoretically, it should be flexible enough even when the end of the scope is very angulated, thereby enabling easy access to difficult locations such as the pancreatic head and uncinate process from the duodenum.

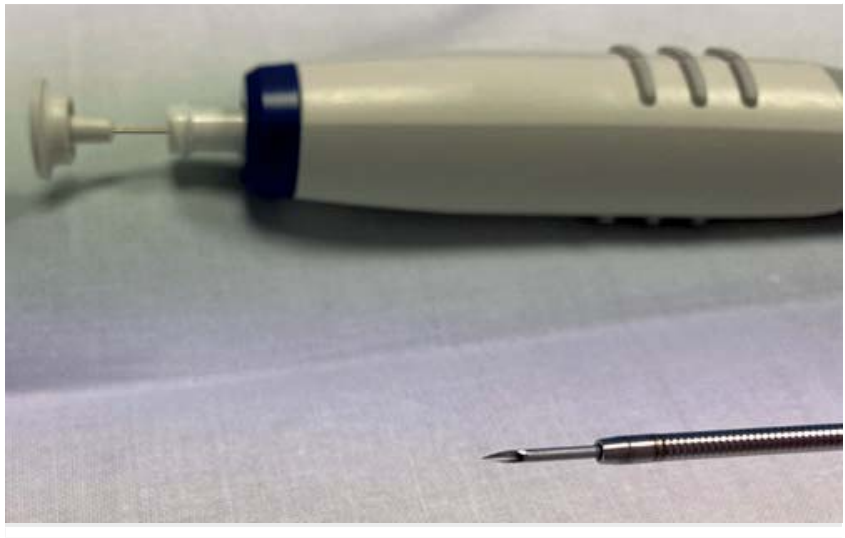

Fig. 1 New nitinol $19 \mathrm{G}$ needle with a multilayer coil sheath and a Menghini tip.

\section{Patients and methods}

\section{Study design}

This was a prospective, multicenter, single-arm study in four tertiary centers in Europe enrolling consecutive patients with solid pancreatic masses in the head or uncinate process of the pancreas referred for EUS-guided tissue sampling.

We used the following exclusion criteria: coagulation disorders (international normalized ratio $>1.5$, platelets $<100,000$ ), post-surgical anatomy (Roux-en-Y gastric bypass, esophagectomy, etc.) that prevented reaching the duodenum, pregnant women, age $<18$ years and refusal to provide written consent. The study was approved by the Institutional Review Boards of all participating centers.

\section{EUS-guided tissue sampling technique}

EUS-guided tissue sampling was performed using a linear array echoendoscope and a 19 G EZShot 3 Plus needle (Olympus, Tokyo, Japan) (\Fig. 1). The procedure was performed under either conscious or deep sedation in all cases.

Once the needle tip was introduced into the target lesion, the stylet was removed, and $5-\mathrm{mL}$ suction was applied with a $10-\mathrm{mL}$ syringe while the needle was moved back and forth eight to 10 times within the lesion (fanning technique). When ROSE was available, it was performed according to the local protocols. A maximum of four passes were allowed. In case of technical failure or inadequate sample for diagnosis, a standard $22 \mathrm{G}$ or $25 \mathrm{G}$ needle was used at the discretion of the endoscopists and specimens were separately analyzed.

The patients were kept under observation for 4 to 8 hours after the procedure. Data concerning postprocedural abdominal pain, bleeding, fever or any other symptoms were recorded to assess the rate and type of possible early adverse events (AEs). AE was defined, following the lexicon of American Society of Gastrointestinal Endoscopy Workshop, as an event that prevents completion of the EUS-guided tissue sampling and/or results in admission to hospital, prolongation of existing hospital stay, another procedure (needing sedation/anesthesia), or subsequent medical consultation [22]. Late AEs were assessed by phone call 7 and 21 days after the procedure. 
The final diagnosis was based on surgical pathology from the resected specimen when available or on malignant histology or cytology in patients managed without surgery. A benign diagnosis had to be supported by other imaging techniques, negative tumoral markers, and a 6-month uneventful follow-up.

\section{Sample processing}

In centers where ROSE was available, some of the slides were stained with a quick panoptic stain for immediate review and verification of the adequacy of the specimen. The rest of the slides were fixed in alcohol and processed in the laboratory. If any tissue fragment was obtained, it was carefully separated from the slide and fixed in formalin, embedded in paraffin, and stained with hematoxylin and eosin for histopathological evaluation ( $\mathbf{F i g . 2}$ ). When on-site evaluation was not possible, the slides were fixed in alcohol and sent to the laboratory for further manipulation and analysis. The first pass with the study needle was analyzed separately, whereas subsequent passes with the same needle were analyzed cumulatively.

\section{Definitions}

Technical success was defined as successful completion of all steps from needle insertion into the echoendoscope accessory channel to tissue procurement. Inability to complete any step above was defined as a technical failure.

Technical feasibility was defined as the ability to reach the lesion with the needle was evaluated with a subjective scale ranging from 1 to 5: 1. Very easy; 2. Easy; 3: Average; 4. Difficult; 5 . Very difficult.

\section{Endpoints}

The primary endpoint was assessment of the technical success of sampling pancreatic solid lesions in the head/uncinate process through the duodenum with the study needle. The secondary endpoints were evaluation of the yield of the first pass with the study needle and assessment of the rate and type of AEs.

\section{Statistical analysis}

Continuous variables were expressed as mean \pm standard deviation. The rate of technical success of the needle, the adequacy of the sample for both cytological and histological diagnosis, macroscopic evaluation of the sample and ancillary techniques as well as the rate and type of AEs were expressed as a percentage.

Calculations were performed for an intention-to-treat (ITT) and per protocol analysis (PP). The study population for the ITT analysis included all patients who were included in the study whereas the PP analysis included only the cases with technical success of the needle. Sample size calculation was performed assuming from previous data [19] that the rate of technical success of the standard $19 \mathrm{G}$ needle is $75 \%$ and with the new needle would be $95 \%$. In order to obtain a precision of $5 \%$ in the estimation of the success proportion by a two-sided $95 \%$ confidence interval, it was necessary to include 73 patients in the study [23]. $P<0.05$ was considered statistically significant.

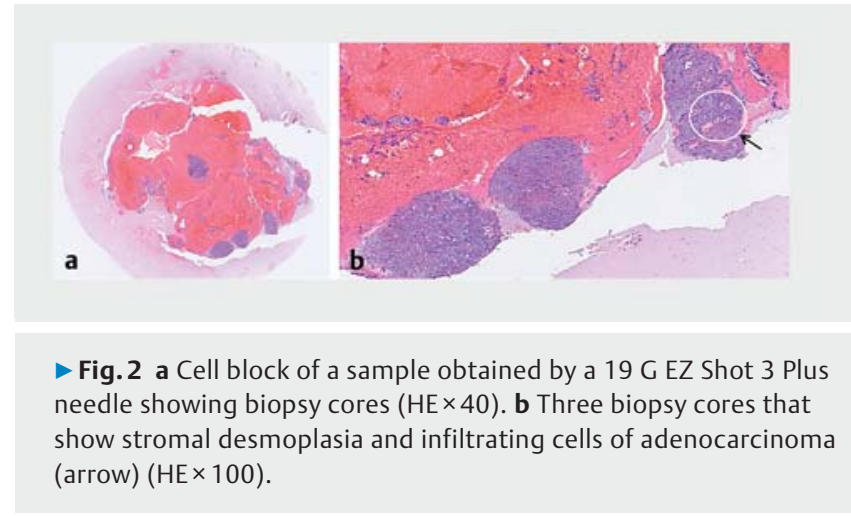

\section{Results}

Between March 2018 and February 2019, 85 patients were eligible for the study. After excluding 10 (coagulation disorders $n=2$, post-surgical anatomy alteration $n=4$ and refusal to provide written informed consent $n=4$ ), 75 patients were included. Most of the lesions were located in the head of the pancreas ( $n=68 ; 91 \%$ vs. $n=7 ; 9 \%$ in the uncinate process). Main characteristics of the patient population are described in $>$ Table 1.

Technical success was achieved in 71 patients (94.6\%). The reasons for the four technical failures were a very difficult position $(n=2)$, duodenal stenosis $(n=1)$ and the presence of periduodenal varices $(n=1)$ that prevented a correct insertion of the needle. A diagnosis was reached in 67 patients, resulting in a PP diagnostic yield of $94.4 \%$ and an ITT diagnostic yield of $89.3 \%$.

Macroscopic evaluation of the samples and other details of EUS-guided tissue sampling are described in > Table 2. ROSE was performed in 40 cases (53\%) with no differences between ROSE and non-ROSE groups regarding diagnostic success (87.5\% vs $91 \% ; P=0.582$ ). The number of needle passes was lower with ROSE than without $(1.4 \pm 0.9$ vs $2.2 \pm 0.7 ; P<0.001$ ( $\triangleright$ Table 2). First pass was evaluated separately in 67 cases, either in the endoscopy room when ROSE was available $(n=40)$ or in the pathology lab $(n=27)$. Diagnosis at the first pass was reached in 50 of 67 (75\%). Tissue for histology was obtained in 64 patients (ITT: $85.3 \%$, PP: $90 \%$ ). In the 15 cases in which inmunohistochemistry was deemed to be necessary, it could be obtained in all but two. A summary of the performance of the study needle is shown in $>$ Table 3.

Concerning technical feasibility, the access of the needle into the lesion was considered satisfactory by the endosonographer in all cases, with $80 \%$ of cases being better than or within average.

In seven of eight patients in whom the study needle failed, an alternative needle was used in the same lesion, whereas in the remaining case, a different lesion was targeted. Details related to the workup for diagnosis in these patients are shown in $>$ Fig. 3 and $>$ Table 4.

Patients were followed up for AEs a mean of $16 \pm 9.4$ days (range $0-37$ ). A total of 38 patients (50.6\%) could not complete the follow-up because they underwent either surgery $(n=12$, $16 \%)$ or ERCP ( $n=26,35 \%)$ earlier than 21 days after EUS. How- 
- Table 1 Main characteristics of the patient population.

\begin{tabular}{|l|c|}
\hline \multicolumn{1}{|l|}{ N $=75$} \\
\hline Sex & $38(51 \%)$ \\
\hline - Male & $37(49 \%)$ \\
\hline - Female & $65 \pm 13(32-88)$ \\
\hline Age, years (mean \pm SD, range) & $59(78.7 \%)$ \\
\hline Symptoms (jaundice, pain, weight loss) & $9(12 \%)$ \\
\hline Anticoagulants or antiplatelets & \\
\hline Location & $68(91 \%)$ \\
\hline - Head & $7(9 \%)$ \\
\hline - Uncinated process & $33 \pm 12(12-80)$ \\
\hline Size, mm (mean \pm SD, range) & \\
\hline Final diagnosis & $59(78.7 \%)$ \\
\hline - Adenocarcinoma & $5(6.7 \%)$ \\
\hline - NET & $2(2.7 \%)$ \\
\hline - Metastases & $2(2.7 \%)$ \\
\hline - Lymphoma & $2(2.7 \%)$ \\
\hline - Chronic pancreatitis & $1(1.3 \%)$ \\
\hline - Metastatic lymph node & $1(1.3 \%)$ \\
\hline - Sarcoma & $1(1.3 \%)$ \\
\hline - Serous cystoadenoma & $1(1.3 \%)$ \\
\hline - GlST & $1.3 \%)$ \\
\hline NET, neuroendocrine tumor; GIST, gastrointestinal stromal tumor. \\
\hline
\end{tabular}

ever, all of them were fine at that time. Only one AE was recorded $(1.3 \%)$ consisting in a duodenal perforation after ERCP performed in the same session after the EUS-guided sampling.

Regarding the three patients with a diagnosis of benignity, one of them was diagnosed of a pancreatic cancer in the follow-up and the remaining two (one chronic pancreatitis and one serous cystadenoma) were alive and in good condition after 6 months of follow-up.

\section{Discussion}

This European multicenter, prospective and single-arm study demonstrates that a novel nitinol 19 G EUS needle has a high technical success and diagnostic yield in solid lesions in the head and uncinate process of the pancreas, irrespective of the presence of on-site cytopathologist. Moreover, despite previous results showing that large bore needles are not flexible enough and might fail to procure tissue in difficult positions, our results show an acceptable perception of difficulty among the endosonographers.

Conventional $19 \mathrm{G}$ needles are recommended to procure samples with preserved tissue architecture for histologic evalu-
- Table 2 Details of EUS-guided tissue sampling.

\begin{tabular}{|c|c|}
\hline & $N=75$ \\
\hline ROSE & $40(53 \%)$ \\
\hline Adequate sample & $30 / 40(75 \%)$ \\
\hline Number of passes & $1.8 \pm 0.9(1-4)$ \\
\hline \multicolumn{2}{|l|}{ Difficulty ${ }^{1}$} \\
\hline - Very easy & $21(28 \%)$ \\
\hline - Easy & $22(29 \%)$ \\
\hline - Average & $17(23 \%)$ \\
\hline - Difficult & $10(13 \%)$ \\
\hline - Very difficult & $5(7 \%)$ \\
\hline \multicolumn{2}{|l|}{ Macroscopic evaluation } \\
\hline - Non-bloody fragment & $33(44 \%)$ \\
\hline - Bloody fragment & $28(37.3 \%)$ \\
\hline - Non-bloody cytological specimen & $6(8 \%)$ \\
\hline - Bloody cytological specimen & $7(9.3 \%)$ \\
\hline - No sample & $1(1.3 \%)$ \\
\hline Use of an alternative needle & $7(9 \%)$ \\
\hline - $22 \mathrm{G}$ & 5 \\
\hline - $25 \mathrm{G}$ & 2 \\
\hline \multicolumn{2}{|c|}{$\begin{array}{l}\text { EUS, endoscopic ultrasound; ROSE, rapid on-site evaluation. } \\
1 \text { Reasons for difficulty: angulation, stiffness of duodenum, hardness of the } \\
\text { lesion, stent, and collateral vessels. }\end{array}$} \\
\hline
\end{tabular}

ation that may be crucial in a subgroup of diseases such as autoimmune pancreatitis or lymphoma, or when immunohistochemical analysis is mandatory $[3,16]$. In addition, obtaining a core biopsy could make ROSE unnecessary $[17,18]$. Transduodenal EUS-guided sampling using conventional $19 \mathrm{G}$ needles is usually challenging due to their stiffness, technical failure rates being higher than with $22 \mathrm{G}$ or $25 \mathrm{G}$ needles [8]. The only RCT [20] comparing $22 \mathrm{G}$ vs. $19 \mathrm{G}$ standard needles in solid pancreatic masses found significantly higher accuracy for the $19 \mathrm{G}$ needle in the per-protocol analysis. However, in the intentionto-treat analysis, no significant difference in accuracy was demonstrated due to a higher technical failure rate of the $19 \mathrm{G}$ needle when the lesions were in the pancreatic head.

Flexible $19 \mathrm{G}$ needles made of nitinol have been developed to overcome this technical challenge. Itoi et al. [18] evaluated the functional characteristics of different $19 \mathrm{G}$ needles, including standard, nitinol-made, and reverse-bevel needles, by bench simulation for angulation and for resistance to passage under various conditions. The nitinol-made needle showed less resistance to passage in various conditions compared to the other $19 \mathrm{G}$ needles. Varadarajulu et al. [21] demonstrated a technical and diagnostic success of $100 \%$ with a 19 G nitinol needle in a prospective cohort study that included 32 pancreatic head or uncinate masses. In addition, adequate tissue core 
- Table 3 Summary of performance of the study needle.

\begin{tabular}{|l|l|l|l|}
\hline & Total N=75 & $\begin{array}{c}\text { ROSE } \\
\text { N=40 }\end{array}$ & $\begin{array}{c}\text { NoSE } \\
\text { N=35 }\end{array}$ \\
\hline Technical success & & & \\
\hline Diagnostic success & $71(94.7 \%)$ & $32 / 35(91.4 \%)$ \\
\hline & ITT: $67 / 75(89.3 \%)$ & 0.582 \\
\hline Diagnostic success at first pass & PP: $67 / 71(94.4 \%)$ & $35 / 38(92.1 \%)$ & $32 / 33(97 \%)$ \\
\hline Histological sample & $50 / 67(75 \%)$ & \\
\hline Feasibility of ancillary techniques when needed & ITT: $64 / 75(85.3 \%)$ & & \\
\hline Adverse events & PP: $64 / 71(90.1 \%)$ & & \\
\hline ROSE, rapid on-site evaluation. & $13 / 15(86.6 \%)$ & \\
\hline
\end{tabular}

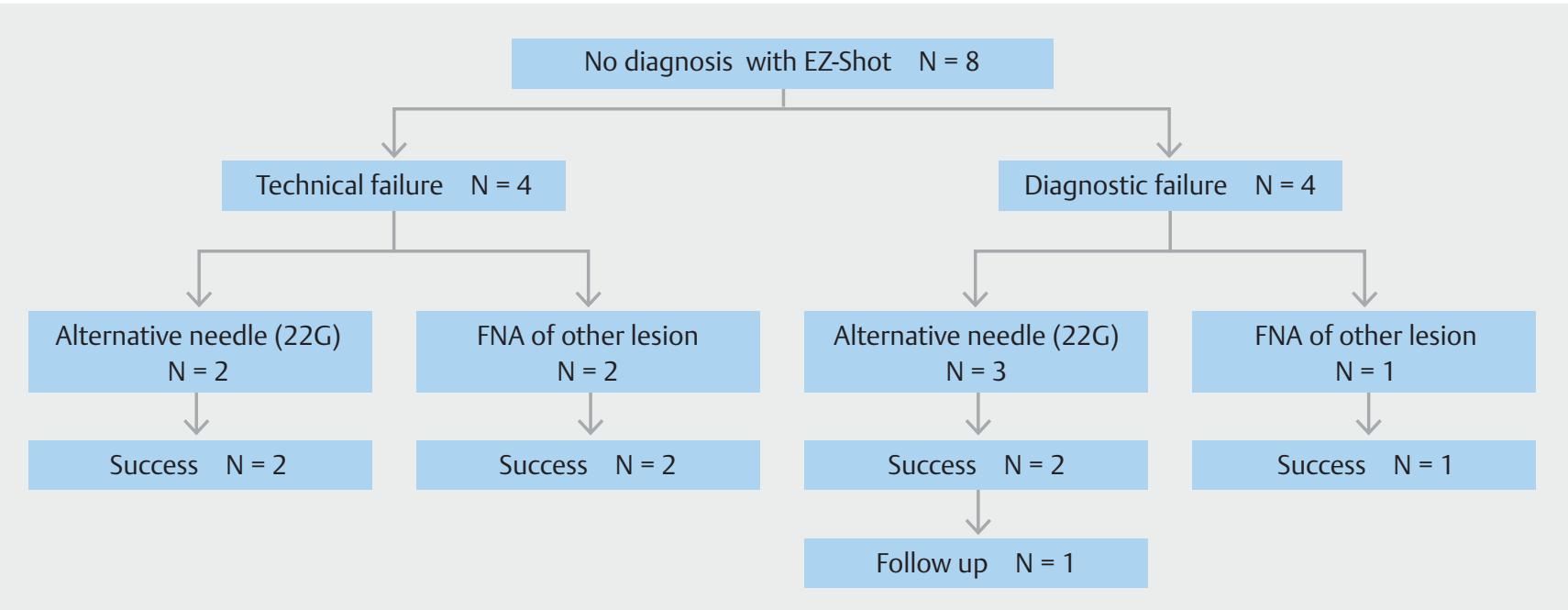

- Fig. 3 Flowchart showing the management of patients in whom the study needle failed.

for histologic examination was obtained in $94 \%$ of patients. However, a recently published multicenter RCT conducted by Laquière et al. [20] compared a $19 \mathrm{G}$ nitinol needle with a standard $22 \mathrm{G}$ needle for transduodenal sampling of pancreatic solid lesions and did not confirm the previous excellent results. With 122 patients included, the diagnostic accuracy of the $19 \mathrm{G}$ and 22 G needles was $69 \%$ and $87 \%$, respectively $(P=0.02)$. Even after exclusion of eight technical failures with the $19 \mathrm{G}$ needle in the per-protocol analysis, there was no diagnostic advantage for the $19 \mathrm{G}$ over the $22 \mathrm{G}$ needle in terms of diagnostic accuracy ( $80 \%$ vs $87 \%, P=0.12$ ). In addition, remarkable technical difficulties were observed in $29 \%$ of patients in whom the $19 \mathrm{G}$ needle was used, as compared with $11 \%$ of patients with the $22 \mathrm{G}$ needle.

Our study shows a $94 \%$ technical success rate with a new nitinol $19 \mathrm{G}$ needle, which is higher than previously reported [24]. This could be related to the innovative design of the needle, featuring a multilayer coil sheath and a Menghini tip that provides a high flexibility even when the end of the scope is very angulated. Our results also show an acceptable perception of technical feasibility since only $20 \%$ of the cases were considered difficult by the endosonographers.

As stated before, advantages of $19 \mathrm{G}$ needles include obtaining tissue core for analysis. In our study, a histological sample was obtained in 64 patients (ITT 85.3\%, PP 90\%) and immunohistochemistry was successful in 13/15 (86\%) lesions in which it was required. This performance is similar to that of other EUS histology needles $[9,25,26]$ and superior to the rate reported with the $22 \mathrm{G}$ and $25 \mathrm{G}$ reverse bevel needles (69\%-83\% and $32 \%-88 \%$, respectively) [27-29].

Although the impact of ROSE on EUS-guided-tissue acquisition in solid pancreatic masses is still controversial $[10,14,15$, 29], this new $19 \mathrm{G}$ needle might provide samples that could obviate the need for ROSE. The results of our study reinforce this assumption because diagnostic accuracy and diagnosis at the first pass did not significantly differ with or without ROSE $(91 \%$ vs $87.5 \%$ and $81 \%$ vs $70 \%$, respectively). 
- Table4 Details about patient diagnostic workup.

\begin{tabular}{|c|c|c|c|c|c|c|c|}
\hline$\#$ & $\begin{array}{l}\text { EZ-shot } \\
\text { passes }\end{array}$ & ROSE & $\begin{array}{l}\text { Alternative } \\
\text { needle }\end{array}$ & $\begin{array}{l}\text { Dx with alter- } \\
\text { native needle }\end{array}$ & Method for final Dx & Final Dx & Comments \\
\hline 1 & 2 & No cells & No & - & FNA another lesion (LN) & NSCLC & $\begin{array}{l}\text { Diagnostic failure. Easy per- } \\
\text { formance }\end{array}$ \\
\hline 2 & 1 & No cells & $25 G$ & No $\mathrm{dx}$ & $\begin{array}{l}\text { FNA another lesion } \\
\text { (pancreatic body) }\end{array}$ & NET & Technical failure. Very difficult \\
\hline 3 & 4 & No cells & $22 \mathrm{G}$ & ADK & Alternative needle & PDAC & $\begin{array}{l}\text { Diagnostic failure. Easy per- } \\
\text { formance }\end{array}$ \\
\hline 4 & 4 & No cells & $22 G$ & ADK & Alternative needle & PDAC & $\begin{array}{l}\text { Diagnostic failure. Easy per- } \\
\text { formance }\end{array}$ \\
\hline 5 & 1 & No cells & $22 \mathrm{G}$ & ADK & Alternative needle & PDAC & Technical failure. Very difficult \\
\hline 6 & 1 & - & $25 G$ & ADK & Alternative needle & PDAC & Technical failure. Very difficult \\
\hline 7 & 3 & - & $22 \mathrm{G}$ & $\begin{array}{l}\text { Chronic pan- } \\
\text { creatitis }\end{array}$ & Follow up & PDAC & $\begin{array}{l}\text { Diagnostic failure. Easy per- } \\
\text { formance }\end{array}$ \\
\hline 8 & 2 & - & $22 \mathrm{G}$ & No dx & FNA another lesion (LN) & PDAC & Technical failure. Very difficult \\
\hline
\end{tabular}

There might be concern about incurring more AEs by using 19 G EUS needles as opposed to thinner needles. However, the use of a nitinol 19 G EUS needle through the duodenum in our study proved to be safe. One patient experienced retroperitoneal perforation during ERCP performed in a single session after EUS. Therefore, we assume that this AE cannot be primarily attributed to the use of the study needle.

The high number of patients included in this multicenter investigation strengths the validity of the results. Moreover, AEs can be correctly assessed only in a prospective fashion such as done in the present study.

Our study presents some limitations. First, because it was the first study with this new nitinol Menghini tip $19 \mathrm{G}$ needle, we did not perform a randomized trial with other EUS needles. Consequently, direct comparisons in terms of technical success and diagnostic accuracy cannot be drawn. Second, only highly experienced endosonographers were involved, limiting its generalizability to centers with less experience. Last, the lack of a centralized cytopathological evaluation that could be considered a limitation of the study did not have a negative impact on the results, considering the high diagnostic yield achieved.

\section{Conclusions}

In conclusion, our data indicate that EUS-guided tissue acquisition of pancreatic solid lesions in the head/uncinate process using a new nitinol Menghini tip $19 \mathrm{G}$ needle is technically feasible and safe with a high percentage of diagnoses at the first pass. Randomized comparative trials are warranted to assess the actual advantages of this new nitinol needle over other EUS needles.

\section{Competing interests}

Dr. Fernández-Esparrach has received fees for organizing courses for Norgine Iberia and Olympus Spain in the last 2 years and has been a consultant for trial design for CDx Diagnostics. Dr. Ginès has been a consultant for Cook Medical and Olympus Europe.

\section{References}

[1] Puli SR, Bechtold ML, Buxbaum JL et al. How good is endoscopic ultrasound-guided fine-needle aspiration in diagnosing the correct etiology for a solid pancreatic mass? A meta-analysis and systematic review. Pancreas 2013; 42: 20-26

[2] Fusaroli P, Kypraios D, Eloubeidi MA et al. Levels of evidence in endoscopic ultrasonography: A systematic review. Digest Dis Sci 2012; 57: 602-609

[3] Dumonceau JM, Deprez PH, Jenssen CA et al. Indications, results, and clinical impact of endoscopic ultrasound (EUS)-guided sampling in gastroenterology: European Society of Gastrointestinal Endoscopy (ESGE) Clinical Guideline - Updated January 2017. Endoscopy 2017; 49: 695-714

[4] Jenssen C, Hocke M, Fusaroli P et al. EFSUMB Guidelines on Interventional Ultrasound (INVUS), Part IV - EUS-guided interventions: General Aspects and EUS-guided Sampling (Short Version). Ultraschall in der Medizin 2016; 37: 157-169

[5] Fusaroli P, Kypreos D, Alma Petrini CA et al. Scientific publications in endoscopic ultrasonography: Changing trends in the third millennium. J Clin Gastroenterol 2011; 45: 400-404

[6] Polkowski M, Jenssen C, Kaye P et al. Technical aspects of endoscopic ultrasound (EUS)-guided sampling in gastroenterology: European Society of Gastrointestinal Endoscopy (ESGE) Technical Guideline. Endoscopy 2017; 49: 989-1006

[7] Bang JY, Hebert-Magee S, Ramesh J et al. Randomized trial comparing the fanning with standard technique for endoscopic ultrasoundguided fine needle aspiration of solid pancreatic mass lesions. Endoscopy 2013; 45: 445-450 
[8] Varadarajulu S, Fraig M, Schmulewitz N et al. Comparison of EUSguided 19-gauge Trucut needle biopsy with EUS-guided fine-needle aspiration. Endoscopy 2004; 36: 397-401

[9] Fernández-Esparrach G, Sendino O, Solé M et al. EUS-guided trucut biopsy in the diagnosis of gastric stromal tumors: a randomized crossover study. Endoscopy 2010; 42: 292-299

[10] Kong F, Zhu J, Kong X et al. Rapid on-site evaluation does not improve endoscopic ultrasound-guided fine needle aspiration adequacy in pancreatic masses: a meta-analysis and systematic review. PLoS One 2016; 11: e0163056

[11] Iglesias-Garcia J, Dominguez-Munoz JE, Abdulkader I et al. Influence of on-site cytopathology evaluation on the diagnostic accuracy of endoscopic ultrasound-guided fine needle aspiration (EUS-FNA) of solid pancreatic masses. Am J Gastroenterol 2011; 106: 1705-1710

[12] Wani S, Mullady D, Early DS et al. The clinical impact of immediate onsite cytopathology evaluation during endoscopic ultrasound-guided fine needle aspiration of pancreatic masses: a prospective multicenter randomized controlled trial. Am J Gastroenterol 2015; 110 1429-1439

[13] Lee LS, Nieto J, Watson RR et al. Randomized noninferiority trial comparing diagnostic yield of cytopathologist-guided versus 7 passes for EUS-FNA of pancreatic masses. Dig Endosc 2015; 28: 469-475

[14] Hebert-Magee S, Bae S, Varadarajulu $S$ et al. The presence of a cytopathologist increases the diagnostic accuracy of endoscopic ultrasound-guided fine needle aspiration cytology for pancreatic adenocarcinoma: a meta-analysis. Cytopathology 2013; 24: 159-171

[15] Matynia AP, Schmidt RL, Barraza G et al. Impact of rapid on-site evaluation on the adequacy of endoscopic-ultrasound guided fine-needle aspiration of solid pancreatic lesions: a systematic review and metaanalysis. J Gastroenterol Hepatol 2014; 29: 697-705

[16] Ginès A. Novel design fine-needle biopsy needles are ready to take over the supremacy of fine-needle aspiration needles for sampling of solid pancreatic masses. Endoscopy 2020; 52: 427-428

[17] Song T], Kim JH, Lee SS et al. The prospective randomized, controlled trial of endoscopic ultrasound-guided fine-needle aspiration using 22 $\mathrm{G}$ and $19 \mathrm{G}$ aspiration needles for solid pancreatic or peripancreatic masses. Am J Gastroenterol 2010; 105: 1739-1745

[18] Itoi T, Itokawa F, Sofuni A et al. Evaluation of 19-gauge endoscopic ultrasonography aspiration needles using various echoendoscopes. Endosc Int Open 2013; 1: E24-E30
[19] Tang S-J, Vilmann AS, Saftoiu A et al. EUS Needle Identification Comparison and Evaluation study (with videos). Gastrointest Endosc 2016; 84: 424-433.e2

[20] Laquière A, Lefort C, Maire F et al. 19 G nitinol needle versus $22 \mathrm{C}$ needle for transduodenal endoscopic ultrasound-guided sampling of pancreatic solid masses: a randomized study. Endoscopy 2019; 51: 436-443

[21] Varadarajulu S, Bang JY, Hebert-Magee S. Assessment of the technical performance of the flexible 19-gauge EUS-FNA needle. Gastrointest Endosc 2012; 76: 336-343

[22] Cotton PB, Eisen GM, Aabakken L et al. A lexicon for endoscopic adverse events: report of an ASGE workshop. Gastrointest Endosc 2010; 71: 446-454

[23] Fleiss JL, Levin B, Paik MC. Statistical Methods for Rates and Proportions. 3rd ed. New York: John Wiley \& Sons; 2003

[24] Adler DG, Witt B, Chadwick B et al. Pathologic evaluation of a new endoscopic ultrasound needle designed to obtain core tissue samples: A pilot study. Endosc Ultrasound 2016; 5: 178-183

[25] Nayar MK, Paranandi B, Dawwas MF et al. Comparison of the diagnostic performance of 2 core biopsy needles for EUS-guided tissue acquisition from solid pancreatic lesions. Gastrointest Endosc 2017; 85: 1017-1024

[26] Alatawi A, Beuvon F, Grabar S et al. Comparison of 22G reverse beveled versus standard needle for endoscopic ultrasound-guided sampling of solid pancreatic lesions. United European Gastroenterol J 2015; 3: 343-352

[27] Park SW, Chung MJ, Lee SH et al. Prospective study for comparison of endoscopic ultrasound-guided tissue acquisition using 25- and 22gauge core biopsy needles in solid pancreatic masses. PLoS One 2016; 11: e0154401

[28] Larghi A, Iglesias-Garcia J, Poley JW et al. Feasibility and yield of a novel 22-gauge histology EUS needle in patients with pancreatic masses: a multicenter prospective cohort study. Surg Endosc 2013; 27: 3733-3738

[29] Hewitt MJ, McPhail MJ, Possamai L et al. EUS-guided FNA for diagnosis of solid pancreatic neoplasms: a meta-analysis. Gastrointest Endosc 2012; 75: 319-331 